\title{
A PESSOA IDOSA E A BUSCA DO SENTIDO. UM OLHAR DE ESPERANÇA
}

\author{
The Elderly Person and the Search of Sense. A Look of Hope \\ La Persona Anciana y la Busca por la Significación. Una Mirada de Esperanza
}

Cleia Zanatta

Luís ANTÔNIO MonTEIro CAMPos

Patricia Damiana da Silva Coelho

\begin{abstract}
Resumo: O presente artigo tem por objetivo propor uma reflexão a respeito da importância do sentido de vida para a pessoa idosa. Sabe-se que o fenômeno do envelhecimento ganha visibilidade no mundo todo e aponta para inúmeros desafios, especialmente para cerca dos 30 milhões de idosos no Brasil, conforme estatísticas do IBGE. Nessa fase da vida, reconhecer as potencialidades, para além dos estereótipos sobre o envelhecer, contribui para minimizar os possíveis desafios. Por meio da revisão de literatura sobre as pesquisas no campo do envelhecimento, constata-se que um número significativo desses idosos concentra-se nas perdas e declínios ocorridos nessa etapa. Entretanto, torna-se possível ampliar a compreensão dessa fase da vida, considerando os conceitos da Logoterapia. De acordo com Viktor Frankl, o ser humano, dotado de sua dimensão noética, impulsionado pela busca de sentido na vida, caminha na busca dos valores de criação, vivência e atitude. Como buscador do sentido, a pessoa do idoso torna-se capaz de encontrar, em sua caminhada existencial, um para quê viver que a possibilite prosseguir extraindo sentido nas situações adversas da vida. Poder debruçar sobre as conquistas realizadas no caminho, os desafios enfrentados e as experiências reconhecidas como valorosas podem contribuir para que a etapa do envelhecimento seja plena de sentido. Os valores podem continuar como caminhos que apontam para o sentido, e tal possibilidade não se deve desperdiçar na estrada da vida. Com esperança e sabedoria acumulada, o idoso é capaz de responder ao que vida chama de modo comprometido e com sentido.
\end{abstract}

Palavras-chave: Idoso; Logoterapia; Sentido.

\begin{abstract}
The purpose of this article is to propose a reflection on the importance of the meaning of life for the elderly person. It is known that the phenomenon of aging gains visibility worldwide and points to numerous challenges, especially for some 30 million elderly people in Brazil, according to IBGE statistics. At this stage of life recognizing the potential, beyond stereotypes about aging contributes to minimizing the possible challenges. Through the review of the literature on research in the field of aging it is observed that a significant number of these elderly people are concentrated in the losses and declines that occurred in this stage. However, it becomes possible to broaden the understanding of this phase of life by considering the concepts of Logotherapy. According to Viktor Frankl, the man, endowed with his noetic dimension, driven by the search for meaning in life, walks in search of the values of creation, experience and attitude. As a sense-seeker, the elderly person becomes capable of finding, in his existential walk one for which to live, which enables him to continue drawing meaning in the adverse situations of life. Being able to focus on achievements along the way, the challenges faced, and the experiences recognized as valuable, can help make the stage of aging meaningful. Values can continue as paths that point to meaning, and such a possibility should not be wasted on the road of life. With hope and accumulated wisdom, the elderly person is able to respond to what life calls in a committed and meaningful way.
\end{abstract}

Keywords: Elderly; Logotherapy; Meaning.

Resumen: El presente artículo tiene por la finalidad proponer una reflexión a respecto de la importancia del significado de la vida para la persona de edad. Conociendo que o fenómeno de lo envejecimiento tiene ganado visibilidad por todo el mundo e indica desmedidos desafíos principalmente por 30 millones de ancianos en Brasil, de acuerdo o censo del IBGE. En ese momento de la vida, reconocer sus potencialidades además de los estereotipos a cerca de envejecer, contribuye reduciendo los posibles desafíos. A través de la revisión literaria sobre los estudios en lo ámbito del envejecimiento, se ha observado que muchos de estos ancianos se concentran en las perjuicios y descenso que se pasan en ese momento de la vida. Entretanto, se e posible amplia la comprensión en esta fase de la vida, teniendo en consideración los conceptos de la Logoterapia. De acuerdo a Viktor Frankl, el hombre, dotado de su magnitud noética e impulsado por la busca por lo sentido de vida, busca los importes de su creación, vivencia y actitud. Para encontrarse como protagonista de su busca por sentido, durante su caminada existencial tornarse capacitado de ir en encuentro con el designio de lo vivir haciendo posible siguieren extrayendo sentido de las dificultades. Al mirar sus conquistas realizadas, los desafíos enfrentados y sus vivencias quedaren reconocidas pueden aportar a un envejecimiento pleno sentido. Los valores pueden quedarse en caminos apuntados a lo sentido y teniendo la posibilidad no se debe desperdiciar por la ruta de vida. Con esperanza y sabiduría acumuladas, el anciano puede responder de modo comprometido y con sentido a él vivir.

Palabras clave: Anciano; Logoterapia; Sentido. 


\section{Introdução}

As estatísticas surpreendem com o avanço da população idosa; aproximadamente o número de brasileiros com mais de 60 anos superou os 30 milhões em 2017, segundo a Pesquisa Nacional por Amostra de Domicílios Contínua (PNAD) divulgada pelo Instituto Brasileiro de Geografia e Estatística (IBGE, 2017). O envelhecimento populacional suscita questões fundamentais para todos os campos de saberes.

As ciências humanas convergem para o estudo desse processo da vida, e, no campo da Psicologia do Desenvolvimento, especialistas, em sua maioria, concordam que esse processo ocorra em etapas ou fases, num dinamismo natural da vida do homem. A Gerontologia surge como um campo de estudos que contempla o envelhecer, mas não se aplica somente à compreensão dessa fase, mas incluem modos de intervenção e cuidados, envolvendo a interdisciplinarmente dos vários saberes, a fim de promover qualidade de vida para os idosos.

Mais recentemente, a Logoterapia e Análise Existencial despontam como a Terceira Escola de Viena, criada por Viktor E. Frankl. Dentre a compreensão dos fenômenos da pessoa humana, esta escola traz uma contribuição valorosa em relação ao pressuposto de que o ser humano é movido pela busca de sentido. Esse sentido pode ser encontrado por intermédio dos caminhos dos valores: os de criação, os de vivência e os de atitude. Tal busca não cessa cronologicamente, mas, como Frankl destaca, "a vida tem sentido sempre, literalmente até o último suspiro, e um sentido incondicionado" (Frankl, 2016, p. 41).

Torna-se um dos grandes desafios, para os profissionais envolvidos nesse campo de trabalho, pensar em como considerar a etapa de envelhecimento de acordo com um tempo de plenitude e não simplesmente na condição de uma etapa de perdas, deterioração e declínio na vida do idoso. De que maneira responder à inquietante e recorrente pergunta de alguns dos idosos, no que diz respeito ao seu porquê viver, e auxiliá-los, no campo das possibilidades, a encontrar o seu para quê viver?

O presente trabalho tem o objetivo de ampliar a visão do conceito de pessoa idosa sob o olhar da Logoterapia, direcionando-a para a compreensão esperançosa de que o ser humano, dispondo de uma dimensão noética, pode viver essa etapa de envelhecimento como um tempo de plenitude e não simplesmente como declínio. A valorização da pessoa idosa e de suas conquistas feitas no caminho, sobretudo na busca de significado na vida, contribuem para o seguimento de sua missão, até o último instante de sua existência.

O referido artigo trata-se de um estudo bibliográfico, apoiado no material teórico da Gerontologia e bases teóricas da Logoterapia, no intuito de propor uma reflexão a respeito da importância do sentido de vida para a pessoa idosa, considerando contribuições sobre as características do idoso na visão da Gerontologia, os estereótipos sobre o envelhecer presentes em nossos dias, as contribuições da Logoterapia quanto à vivência de valores e estimular os profissionais da área sobre como podem contribuir para compreensão e acolhimento dessa etapa de vida tão rica de valores.

\section{Idoso e a Gerontologia}

A Gerontologia compreende os estudos sobre o processo de envelhecimento e considera a importância das intervenções multidimensionais, de acordo com Papalia, Olds e Feldman (2007). Busca-se analisar as experiências sobre o envelhecer em diferentes contextos socioculturais e históricos, abrangendo aspectos do envelhecimento normal e patológico. Esse campo de estudos serve de suporte aos profissionais em campo, contribuindo para uma ampla visão sobre a pessoa do idoso em nossa sociedade.

A produção de conhecimento, juntamente com o avanço das tecnologias, a queda da taxa de natalidade, a melhoria nas condições sanitárias, dentre outros fatores, possibilitaram que o fenômeno do envelhecimento pudesse ter maior visibilidade no mundo inteiro, sobretudo nos países em desenvolvimento, o que impulsiona a elaboração de medidas e ações de cuidado destinadas para o público em referência.

De acordo com estatísticas do Instituto Brasileiro de Geografia e Estatística (IBGE), em pouco mais de duas décadas, 32,5 milhões de pessoas dentre os 226 milhões de brasileiros terão 65 anos ou mais (Brasil, 2020). A população brasileira manteve a tendência de envelhecimento dos últimos anos e ganhou 4,8 milhões de idosos desde 2012, superando a marca dos 30,2 milhões em 2017, segundo a Pesquisa Nacional por Amostra de Domicílios Contínua - Características dos Moradores e Domicílios, divulgada pelo IBGE (2018).

O cenário populacional sofre mudanças rápidas e simultaneamente surgem impactos socioeconômicos, no campo da saúde, na arquitetura, no direito, na cultura, na assistência social, nas políticas públicas etc. Configura-se uma realidade desafiadora, que mobiliza diversos campos de saberes, a fim de que as ações elaboradas estejam realmente integradas de acordo com as demandas do idoso e, dessa forma, promovam melhorias em sua qualidade vida.

A Organização Mundial da Saúde preconiza como idoso aquele que possui 65 anos nos países desenvolvidos, e 60 anos nos países em desenvolvimento. "No Brasil, de acordo com o Estatuto do Idoso (2003), uma das aquisições legais de relevância para a população idosa, pessoas com idade igual ou superior a 60 anos são reconhecidas como idosas.” (Schneider \& Irigaray, 2008, p. 589).

Embora exista um marcador social e cultural que defina idoso a pessoa com 60 anos, alguns 
pesquisadores da área do envelhecimento referem que esse processo se torna complexo e multifatorial, pois envolvem questões quanto à genética e ao ambiente. "A idade em si não determina o envelhecimento, é apenas um dos elementos presentes no processo de desenvolvimento, servindo como uma referência da passagem do tempo.” (Schneider \& Irigaray, 2008, p. 592).

Outros pesquisadores apontam que, nessa etapa, caracterizada por mudanças fisiológicas, psicológicas e sociais, dentre elas, dificuldades quanto ao funcionamento físico, aparecimento ou o agravamento de doenças somáticas, as falhas na memória, o isolamento social, podem comprometer, na maioria das vezes, a qualidade de vida do idoso (Melo, Eulália, Silva, Silva Filho e Gonzaga, 2013).

Por vezes, o enfoque concentra-se mais nas perdas que ocorrem nessa fase, contribuindo para um envelhecimento marcado por estereótipos, em sua maioria, negativo. Perde-se, com isso, a possibilidade de acolher a beleza das conquistas e feitos que ocorrem nessa etapa. Entretanto, o processo natural que contempla o desenvolvimento humano não se deixa aplacar pelas dificuldades somente; em algumas pesquisas no campo da Gerontologia, vê-se que:

Há ainda os especialistas que se referem a grupos de pessoas mais velhas: os idosos jovens, os idosos velhos e os idosos mais velhos. O termo: idosos jovens geralmente se referem a pessoas de 65 a 74 anos, que costumam estar ativas, cheias de vida e vigorosas. Os idosos velhos, de 75 a 84 anos, e os idosos mais velhos, de 85 anos ou mais, são aqueles que têm maior tendência para a fraqueza e para a enfermidade, e podem ter dificuldade para desempenhar algumas atividades da vida diária. (Papalia, 2006 citado por Schneider, 2008, p. 586)

Outra variável importante para mencionar nesse caminho de compreensão quanto ao fenômeno do envelhecer refere-se à representação da figura do idoso em nosso meio. Vê-se, ao longo da história, que a imagem do idoso vem sofrendo modificações:

Assim, nas sociedades primitivas, os velhos eram objetos de veneração, os jovens a eles recorriam em busca de seus conselhos; os idosos de então eram respeitados, a ponto de se lhes confiarem negócios de grande importância social e econômica. Confúcio (nascido em 551 a.C. e falecido em 479 a.C.) considerava que todos os elementos de uma família deveriam obedecer aos mais idosos. (Netto, 1996, p. 9)

O idoso, antes visto como um patrimônio para a sociedade, ao longo do tempo, no contexto social, foi sendo considerado por sua "capacidade de produzir", e o seu "valor”, associado à sua capacidade funcional. Muitos não se preparam para o momento da aposentadoria; menos ainda para a etapa do envelhecer. Cabe, aqui, destacar a relevância dos Programas de Preparação para Aposentadoria, que, dentre as ações que realizam, contempla o preparo emocional na contribuição para um desdobramento diferenciado nessa fase.

Outro aspecto quanto ao termo velho é que no senso comum, algumas vezes, é percebido como uma imagem pejorativa:

Velho é traste, problema, ônus, inutilidade; velhice é doença, incapacidade, dependência, perda, impotência. Velho é uma pessoa que atrapalha as outras, alguém que perdeu o direito à dignidade, à sobrevivência, à cidadania. A imagem que a mídia difunde tradicionalmente é a de uma pessoa encurvada (submissa), de bengala, quase cega, surda e gagá. (Paschoal, 1996, p. 41)

Estereótipos acima mencionados por Paschoal (1996) ainda se encontram presentes nos discursos de idosos em nossos tempos atuais. Compreendem o tempo de envelhecer como um tempo de adoecimento, associado ao impactante medo da morte. A dificuldade de aceitação das mudanças biológicas (cabelos brancos, rugas, as mudanças corporais, reflexos mais lentos etc.), associados à falta de um propósito, torna o tempo da velhice, para muitos, como um tempo indesejável.

Contribuições dos trabalhos de Guita Grin Debert (2004) sugerem e reforçam a necessidade da revisão dos estereótipos associados ao envelhecimento, considerando que o conceito de velhice perpassa pelo contexto social, cultural, geográfico, econômico e, inclusive, pelos novos padrões de aposentadoria, resultando uma nova configuração aos modos de gestão da velhice. Considerando, nesse campo de estudos:

Assim, a transformação do envelhecimento em objeto de saber científico põe em jogo múltiplas dimensões, como desgaste fisiológico e o prolongamento da vida, o desequilíbrio demográfico e o custo financeiro das políticas sociais (Debert, 2004, p. 32).

Uma pesquisa recente elaborada por Neri e colaboradores, no que tange as trajetórias da participação social na velhice, destaca que: "Atualmente, a literatura sobre a experiência de envelhecimento é repleta de considerações relativas à produtividade e ao sucesso, assumindo um tom mais positivo em relação à experiência de envelhecer" (Pinto \& Neri, 2017, p. 261).

Nota-se, inclusive, de forma expressiva e contrastante em muitos contextos familiares, que há também aquele grupo de idosos que permanecem como provedores de suas casas, cuidando dos netos e compartilhando suas aposentadorias. Em 
algumas situações, até buscam novas oportunidades de trabalho para sobrevivência. Parecem lidar com a crise de outra maneira, enfrentando e lançando mão de suas potencialidades. Embora seja possível ter uma visão geral da pessoa idosa nessa fase, entendemos que cada pessoa acolhe a etapa do envelhecimento baseada em seu percurso histórico e singular, confirmando o pensamento do gerontólogo Ajuriaguerra de que na vida: "Envelhece-se como se viveu" (Correa, 2016).

De acordo com os pesquisadores Schneider e Irigaray (2008):

[...] ao mesmo tempo em que a sociedade potencializa a longevidade, ela nega aos velhos o seu valor e sua importância social. Vive-se em uma sociedade de consumo na qual apenas o novo pode ser valorizado, caso contrário, não existem produção e acumulação de capital. Nesta dura realidade, o velho passa a ser ultrapassado, descartado, ou já está fora de moda. (Schneider \& Irigaray, 2008, p. 587)

Percebe-se que as diversas representações sociais da velhice, decorrentes da influência cultural ao qual o idoso encontra-se inserido, favorecem para que ele possa se relacionar de forma negativa ou positiva com essa fase da vida. No âmbito geral, a exigência de cuidados para com o idoso consolida-se no decorrer do tempo envolvendo a sociedade, tal como, por meio de políticas públicas de assistência e promoção de saúde, o suporte familiar e dos profissionais, bem como pela implantação de órgãos de direito, como os Conselhos e o Estatuto do Idoso, que visam à garantia dos direitos e deveres pertinentes ao público em questão.

Medidas de atenção e proteção aos idosos são relevantes, diante de indicadores sociais que apontam dados estatísticos crescentes no que tange as situações de violência e índice de suicídio sofrido pelos idosos no Brasil, onde os esforços de ações continuadas, por parte de todas as esferas da sociedade envolvidas no cuidado ao idoso, são fundamentais. Contudo, mesmo diante da complexidade do processo do envelhecimento, perceber esse tempo da vida como um somatório de sabedoria, com experiências cabíveis de ressignificação, saberes acumulados ao longo dos anos e que precisam ser valorizados, confere a ideia de cuidado sobre o qual, nos alerta Neri, quando destaca que: "Como em qualquer idade, os velhos precisam das redes de relações sociais para saber que são amados, cuidados e valorizados" (Neri, 2009, p. 106).

Nessa perspectiva de cuidado, abrir possibilidades para o ser humano aprender a se relacionar com a temporalidade de uma forma nova, aumentando a percepção dos êxitos e aprendizados existentes nessa etapa do envelhecer, torna-se um caminho desafiador para todos nós.

\section{Logoterapia e o Envelhecimento}

A Logoterapia, criada pelo médico psiquiatra Viktor Emil Frankl (1905-1997), considerada como a Terceira Escola Vienense de Psicoterapia, aponta para a questão do sentido na existência humana. Para Frankl, o ser humano é um ser motivado por uma vontade de sentido, que atua como força motriz, a qual impulsiona o homem na busca por encontrar significado, propósito, enfim, sentido na vida. Esse sentido é individual e, uma vez encontrado, precisa ser realizado pela pessoa que o busca. O ser humano, para Frankl, é "um ser que quer encontrar para toda a sua existência e para cada situação e no interior da mesma um sentido e que depois quer realizá-lo" (Frankl, 2016, p. 17).

Na visão da Logoterapia, a pessoa humana é considerada única e irrepetível. Frankl refere que "cada qual tem sua própria vocação e missão específica na vida; cada um precisa executar uma tarefa concreta que está a exigir realização" (Frankl, 2014, p. 133). Nesse sentido, ninguém pode substituir e responder por aquilo que unicamente um determinado ser humano necessita realizar como sua missão singular. Frankl sinaliza que, apesar dos condicionamentos e influências do meio, o ser humano é sempre capaz de decidir, exercendo sua liberdade e responsabilidade, em vista de encontrar sentidos.

A Logoterapia apresenta uma visão antropológica e filosófica a respeito do ser humano, constituído por três dimensões, a saber:

[...] temos uma dimensão somática (nosso corpo e todo o seu funcionamento), uma dimensão psicológica, (nossa psiquê ou alma) e uma dimensão espiritual. Não é uma soma das três partes, é uma unidade com três diferentes dimensões. É a dimensão espiritual que garante a unidade do ser humano, como um eixo que perpassa e une as outras dimensões. (Kroeff, 2014, p. 194)

Cada dimensão tem sua relevância específica para o ser humano, porém é a dimensão espiritual (ou noética), que caracteriza a pessoa humana, pois, justamente nessa dimensão, encontra-se o que há de mais humano no humano, "os valores, a capacidade de escolha, a possibilidade de distanciar-se e de transcender aos eventos e aos condicionamentos que ocorrem nas outras duas dimensões" (Kroeff, 2014, p. 194).

No decorrer de nossa existência, a vida nos chama a dar respostas com as nossas decisões, escolhas e atitudes. Cada situação experimentada nos permite desenvolver uma importante capacidade, "a autotranscendência, capacidade de ir além de mim mesmo, na direção de alguma causa a que sirva ou de alguma pessoa a quem amo. E é somente na medida em que o ser humano se autotranscende que lhe é possível realizar-se” (Frankl, 2016, p. 25). 
Nessa busca para encontrar sentidos na vida, a Logoterapia aponta três categorias essenciais para vida do homem. Refere-se aos valores de criação, de vivência e de atitude. De acordo com Frankl, podemos descobrir o sentido: "1- criando um trabalho ou praticando um ato; 2- experimentando algo ou encontrando alguém. 3- pela atitude que tomamos em relação ao sofrimento inevitável” (Frankl, 2014, p. 135).

O valor de criação trata de tudo o que a pessoa realiza, oferece ao mundo, por meio de seu trabalho, daquilo que cria e produz. De acordo com Kroeff (2014), importa o valor atribuído ao nosso fazer, à nossa tarefa. "O valor de criação é algo que podemos exercer uma boa parte de nossa vida, às vezes até o fim da vida” (Kroeff, 2014, p. 197). Na verdade, não se aposenta da vida e muito menos das possibilidades que ela oferece. Porém, comumente, após o processo de aposentadoria, alguns idosos questionam-se sobre o propósito de suas vidas, uma vez que a atividade laboral não mais exercida permite o tempo livre, e muitos se interrogam se vale a pena viver.

O sentimento de inutilidade por não estar mais inserido no mercado de trabalho, a sensação de apatia e a falta de valor surgem para um grande número deles. A sensação de "vazio existencial” pode emergir aqui, sobretudo se a atividade profissional for considerada como o valor mais relevante em referência ao valor criativo. Porém, na medida em que o idoso pode ampliar o valor criativo, não fixando unicamente na atividade profissional, mas redirecionando-o para outros valores de criação, pode-se contribuir para um tempo mais ameno na vida dos idosos (Kroeff, 2014).

Quando nos referimos ao vazio existencial, de acordo com Rodrigues (1991):

Nesse estado, as pessoas sentem uma espécie de tédio e fastio interno. A "neurose de domingo" seria um bom exemplo de "estado de vazio existencial”, onde uma falta de significado das coisas e uma prostração ou depressão se apossa das pessoas exatamente nos dias em que elas não podem fugir do "vácuo" através das atividades rotineiras que mascaram o quadro, (Rodrigues, 1991, p. 59)

O valor de vivência "são aqueles bens que recebemos da vida, simplesmente por viver, nas nossas relações com as outras pessoas, com a natureza e com o mundo" (Kroeff, 2014, p.198). Ajuda-nos a expressar nossa capacidade de amar algo ou alguém, possibilita-nos estabelecer vínculos através das amizades e da experiência do amor. A vivência desse valor não fica restrita a uma cronologia.

A velhice pode ser uma época em que os valores de vivência assumam uma grande importância, [...] a pessoa tem um tempo maior para suas vivências, sem a pressão de ter que realizar, produzir, trabalhar, enfim. Pode, talvez, desfrutar da vida, sem maiores pressões ou preocupações. (Kroeff, 2014, p. 198)

Desfrutar da vida sem maiores preocupações possibilita ao idoso tempo para dedicar-se às opções de lazer, ao contato com as realidades da natureza, à participação em atividades de grupos, favorecendo sua rede de contatos e participação social. O tempo livre tem um novo significado para o idoso, e a importância de manter seus projetos de vida ajuda-o para que os valores de vivência sejam mantidos nessa etapa, bem como a retomada de antigos projetos.

Por fim, seguindo por esse caminho dos valores, o ser humano pode deparar-se com situações desafiantes. Frankl (1991) chama de a 'tríade trágica - o sofrimento, a culpa e a morte. E a Logoterapia tem a ousadia de afirmar que estes fatos inevitáveis que acompanham a existência humana também - o sofrimento, a culpa e a morte - "podem trazer oportunidades de sentido à vida" (Kroeff, 2014, p. 199).

São as circunstâncias inesperadas que se apresentam em qualquer época do percurso da vida. $\mathrm{O}$ ser humano, em meio aos desafios, pode posicionar-se diante deles e tem possibilidades de captar sentidos. Isso confere à pessoa a chance de se ter uma postura madura frente à vida que vive. "Somente quando o sofrimento é inescapável, podemos extrair dele um valor de atitude, em vez de submergir em desespero, apatia ou desânimo" (Kroeff, 2014. p. 199).

Frankl, ao abordar o sentido do sofrimento em sua obra, refere que "se pode encontrar o sentido em todas as circunstâncias na vida, mesmo quando nos confrontamos com uma situação sem esperança” (Frankl, 2014, p. 136). O ser humano tem uma capacidade de demonstrar o seu potencial especificamente humano, por meio de seus atos e escolhas, e "transformar uma tragédia pessoal em triunfo, em converter o sofrimento numa conquista diante das situações adversas" (Frankl, 2014, p. 137).

O desafio experimentado no tempo da velhice pode representar, para muitos, um "troféu" pessoal. Por exemplo, um idoso que não pode locomover-se com tanta agilidade como antes, que passa a não enxergar com tanta precisão por conta das limitações físicas de que foi acometido, pode abater-se diante das limitações ou ter a possibilidade de tornar essa experiência um "triunfo", valorando o vivido e o experimentado ao longo da existência, justamente quando pode acessar sua dimensão noética e os recursos que o auxiliam a não se paralisar diante das perdas, mas que lhe recordam de sua vida valiosa e digna de ser vivida, encontrando forças para superação desses desafios.

Cabe destacar que, para busca de sentido, não se faz necessário buscar pelo sofrimento. Porém, quando diante dele tem-se a chance de "sofrer com bravura, a vida recebe um sentido até o seu derradeiro instante, 
mantendo esse sentido literalmente até o fim” (Frankl, 2014, p. 138).

Ainda sobre o tempo de envelhecer e o caminho dos valores na busca de sentido, a pessoa idosa desperta para uma consciência de sua finitude. O surgimento dessa consciência pode levá-la ao questionamento; "até quando tenho oportunidade de realizar sentidos?". Isso mobiliza o idoso para o fato da temporalidade, de que ainda se pode realizar sentido na vida, refletindo sobre quais mudanças necessita realizar antes que a morte se apresente. Pode ocorrer, em certas situações, através dos questionamentos do sentido de nossa existência, de ter a impressão que não há um para quê viver (Lukas, 2015).

Elizabeth Lukas (2015) destaca que há "três tempos de questionamentos sobre o sentido da vida, que são impulsos fundamentais para indagar por motivos autênticos para a vida e para sobrevivência, e no caso de encontrá-los, dizer conscientemente "sim" à vida.” (Lukas, 2015, p. 162). Entretanto,

[...] se a pessoa não encontra um sentido autêntico para viver, aumentará rapidamente o perigo de suicídio, sob qualquer forma que seja, não porque subitamente apareceu um motivo grave para morrer, mas porque no estado acordado e estimulado da consciência do ser humano falta a razão para viver. (Lukas, 2015, p. 162-163)

Torna-se relevante para cada pessoa, sobretudo aos idosos, estar atenta ao que a vida continua a lhe perguntar e a convocar como tarefa a ser realizada no percurso da sua existência. Nas fases particularmente difíceis da vida, destaca Lukas (2015), o enfoque está nas perdas dos valores que julgamos pertencer-nos. "Os valores não existem no espaço do ter. Eles vêm e vão, tocam-nos e movemnos em esferas espirituais, acompanham-nos na caminhada através das diferentes faixas etárias e os valores nos falam das maravilhas do mundo" (Lukas, 2015, p. 164). que:

Lukas pontua que os valores são tão preciosos

Manifestam-se no rosto de uma pessoa amada, da mesma forma como na alegria produzida por uma bela música ou fascinação exercida por uma ação convincente. Contudo, não nos pertencem. $\mathrm{O}$ amado não nos pertence, a arte, o trabalho também não nos pertencem. $\mathrm{O}$ amado nos deixa ou morre. A música não se revela mais a ouvidos surdos e o trabalho nos é tirado o mais tardar na velhice [...]. Motivos suficientes para sinistra atitude de muitos suicidas? Ou magnífico motivo para agradecer o que recebemos, e campo aberto para futuras oportunidades de valorização? (Lukas, 2015, p. 165)
Como pessoa humana, cabe sempre a possibilidade de uma decisão, de uma escolha na vida. Saber reconhecer e valorar as oportunidades recebidas, ter gratidão pelas experiências vivenciadas ampliam para a pessoa idosa as novas possibilidades de oportunidades. O ciclo da vida humana pode continuar com vitalidade e esperança, mas para seguir nesse caminho é preciso certa coragem (Lukas, 2015).

Outra perspectiva relevante que Lukas ressalta, no seu artigo sobre "A questão do sentido na Velhice" (Lukas, 1992, p. 168), refere-se ao movimento que a pessoa idosa realiza ao olhar da plataforma do seu presente, contemplando em três direções distintas, as quais ela denomina de: "Olhar para trás", 'Tarefa presente' e "Olhar para frente".

De modo sucinto, o primeiro movimento referese a uma espécie de balanço existencial, no qual o idoso depara-se com suas experiências do vivido e o não vivido em sua historicidade. Nesse movimento, ele encontra-se com a contribuição que foi prestada para o mundo: tempo de colheita, de sentidos realizados, de êxitos concluídos, bem como as experiências "sofridas". Entretanto, recomenda uma postura reconciliadora nesse olhar retrospectivo, sobretudo no que concerne a esse tempo na vida. No segundo aspecto, cabe ao idoso olhar para tarefa presente e continuar, de modo livre, a responder ao que a vida chama aos desafios do hoje. Por fim, o olhar para frente propõe contemplar o futuro, implica assumir o tempo que se tem e o enfrentamento da saída desse tempo, diante da possibilidade da finitude.

Embasados pela Logoterapia, nós percebemos que a pessoa humana, dotada de sua dimensão somática, está para além de um corpo que envelhece, adoece e enfraquece com o passar do tempo. Mesmo diante de seus maiores desafios na sua história pessoal, continua sendo convocada pela vida para lidar com as situações adversas e, se possível, enfrentá-las com coragem, crescendo na superação de conflitos e dificuldades até o último momento de sua existência. Para tal, contará com a dimensão noética, que lhe confere uma força interna, permitindo-lhe manter sua dignidade diante das dificuldades e poder escolher: "Dizer sim à vida, apesar de tudo" (Frankl, 2014, p. 161).

\section{Envelhecer com Sentido: Caminhos de Esperança}

Atéomomento, percebe-sequeválidas epreciosas são as contribuições dos teóricos da Gerontologia e do campo da Psicologia, mais precisamente, da Logoterapia. Há uma compreensão de que, em relação à fase do envelhecimento notadamente marcado por mudanças, crises e estereótipos, observa-se que estas estão em qualquer etapa do desenvolvimento humano.

O Psicólogo e Logoterapeuta Garcia Pintos concebe as etapas da vida humana referenciando 
as dimensões da estrutura humana, segundo a Logoterapia, permitindo ampliar a visão sobre esse tempo do envelhecimento. Garcia Pintos (1992) destaca que "esta tridimensionalidade nos permite dividir as recorrências evolutivas em três idades (primeira, segunda e terceira idade). Estas idades resultam da inter-relação circular que manifesta alternadamente o predomínio de uma dimensão sobre as demais" (Pintos, 1992, p. 16). Isso não quer dizer que as demais dimensões humanas se tornam nulas ou suprimidas, porém, conforme a etapa vivenciada, há um predomínio de uma sobre a outra.

Conforme Garcia Pintos destaca, na primeira etapa ou a primeira idade, que corresponde do nascimento até a fase pré-adolescente, a dimensão biológica se destaca pelos apelos do plano biológico, tempo de crescimento, amadurecimento das estruturas funcionais, habilidades motoras, entre outras. Em seguida, essa dimensão biológica permanece, porém, a dimensão psicológico-social desponta, na segunda idade, etapa da adolescência até a maturidade. Nesse tempo, a relação com os outros, a participação no meio social, a busca da definição da identidade, o casamento, as escolhas profissionais, os vínculos estabelecidos, as interações sociais, cooperam para o destaque desta dimensão, embora as demais estejam atuando como pano de fundo. Já na terceira idade, o enfoque principal não está na dimensão biológica nem na psicológica, mas a predominância está na dimensão espiritual (ou noética), pois esta aponta para o mundo dos valores (Pintos, 1992).

Sob esse prisma, vê-se um caminho de esperança para o idoso:

A terceira idade não é uma etapa de deterioração ou declínio. Ao contrário é uma idade de plenitude, vitalidade e crescimento. Porque, se consideramos o homem um ser espiritual, seu verdadeiro momento de plenitude não pode ser da plenitude biológica, nem o da plenitude psicossocial, mas o momento áureo da vigência predominante e plena da dimensão espiritual ou noética. (Pintos, 1992, p. 17)

Oidoso pode extrair desse momento de plenitude, a beleza quanto aos valores conquistados, criações realizadas, experiências vividas e reconhecidas como significativas no caminho. Pode acolher esse tempo como crescimento e vitalidade, olhar para o seu "celeiro existencial" e nele encontrar o acúmulo de suas realizações. "Na velhice, é bastante provável que tenha guardado muitos tesouros... as criações, vivências, além das atitudes que fomos adotando e moldaram a nossa vida” (Kroeff, 2014, p. 202).

Mas os tesouros precisam ser compartilhados, e isso se torna um caminho de vitalidade para o idoso: valorizar a conquista do longo caminho percorrido, contar com valores essenciais e a sabedoria singular. Tais aquisições não se perdem no caminho da existência, e, justamente no tempo da velhice, pode ser o tempo do "dar-se" ao mundo, compartilhando os tesouros com os quais o idoso descobre-se capaz de enriquecer outras vidas no seu caminho.

Amatuzzi (2015) descreve que, diante das limitações encontradas no envelhecimento, o encontro com a vida está na superação dos apegos, com a percepção de libertação interior, o que faz a pessoa descer dentro de si mesma. Redescobrir a vitalidade diante da proximidade da finitude, torna o ser humano mais compreensivo e tolerante diante das situações da vida, nas quais a necessidade de sentido torna-se urgente.

Pensar sobre o tempo de finitude, imbuídos dessa visão positiva sobre o envelhecer, pode favorecer a compreensão de que:

[...] a possibilidade da morte não ocasiona um medo desesperador. Na verdade, ela se torna a razão para uma atuação decidida que nos motiva a viver a vida plenamente, sem titubear nem deixar para depois. Por intermédio dela, tomamos consciência de que não temos toda a vida pela frente, toda a eternidade para fazer de nós um ser pleno de sentido, e tudo isso nos mobiliza rumo a uma realização pessoal em comunidade, na mais profunda intimidade com os outros, em resposta a uma solicitude essencial e que constitui o núcleo do compromisso humano. (Pintos 1992, p. 32-33)

Existe um caminho aberto para possibilidades na vida. O tempo presente da existência pode ser vivenciado com mais sabor, sem deixar para depois. Há esperança para esse tempo ser vivido com mais alegria, e a vida continua a convocar, para a partilha dos tesouros, aqueles que são vistos como "os guardiões da memória coletiva”, como citado na Carta do Papa João Paulo II aos Anciãos de $1^{\circ}$ de outubro de 1999:

Os anciãos ajudam a contemplar os acontecimentos terrenos com mais sabedoria, porque as vicissitudes os tornaram mais experimentados e amadurecidos. Eles são guardiões da memória coletiva e, por isso, intérpretes privilegiados daquele conjunto de ideais e valores humanos que mantêm e guiam a convivência social. Excluí-los é como rejeitar o passado, onde penetram as raízes do presente, em nome de uma modernidade sem memória. Os anciãos, graças à sua experiência amadurecida, são capazes de propor aos jovens conselhos e ensinamentos preciosos. (Vaticano, 1999)

Ser considerado como "guardiões" dos valores essenciais da humanidade, dos ensinamentos apreendidos no caminho da vida, por outro ângulo, corrobora com a ideia de Frankl de que há um 
chamado para cada um na existência e, nesse sentido e de certo de modo, um chamado coletivo e pessoal para cada idoso. Como nos diz Garcia Pintos: "Por ser pessoa, o idoso é um buscador de sentido; recuperar a serenidade e alegria de viver dependerá de encontrar em sua idade um espaço significativo de vida." (Pintos, 1992, p. 103).

Imbuído nesse olhar de esperança para com os idosos, um campo aberto de possibilidades apresentase diante dos profissionais envolvidos nessa atividade. Pois, na medida em que espaços de atenção e cuidado existem com essa finalidade, há possibilidade de se partir de uma escuta na qual o idoso refere: estou esperando a hora chegar, para ir além, na verdade, ao encontro do seu "celeiro existencial" e provocálo nesse caminho de reflexão: Enquanto a hora não chegar, o que está no campo de possibilidades, o que posso realizar?

Esta pergunta impulsiona a saída do foco das queixas pelas perdas e declínio, para o foco no potencial do idoso, que se sabe buscador de sentidos. Na prática profissional, a ideia de que não há mais perspectiva na vida pode passar a dar lugar a outros discursos. Considerando a tarefa presente e sua relevância, alguns contemplam que o sentido na vida pode ser encontrado quando conseguem expressar que se sentem realizados ao cuidar do bisneto com alegria, ao visitar uma pessoa que há tempos não encontrava, ao realizar um curso na Paróquia da sua cidade, ao aprender coisas novas numa atividade de artesanato, ao entender os filhos complicados, ao manter o sonho de revisitar sua terra natal, ao ajudar ao próximo, ao acolher bem as pessoas, ao ser solidário, ao sentir-se útil aconselhando os netos, ao estar engajado como voluntário numa instituição de cuidados a crianças portadoras de necessidades, ao educar os membros da família para amar e em tantas outras possibilidades.

Alguns relatam viver essa etapa da vida como um tempo pessoal para uma reforma íntima, um balanço interno, fazendo considerações quanto as suas vivências; outros olham para vida com um olhar mais amoroso, pois há coisas que atualmente se relevam, e se descobrem outras importantes... Sentem que ainda podem ser luz para família. Mesmo parecendo que não há mais tempo para mudar, sentem que podem melhorar como pessoa e recomeçar. Torna-se possível, ao lidar com idosos, vislumbrar caminhos de esperança, pois se sabe que essa força que os impulsionam, pertencente ao ser humano na busca do sentido, encontra-se viva e presente, conduzindoos no seguimento da vida e missão.

\section{Considerações Finais}

O fato de nos depararmos com o aumento da população idosa nos impulsiona ao enfrentamento de muitos desafios. Nossa prática profissional necessita direcionar o olhar para o horizonte da esperança, pois existe um número expressivo de idosos aprisionados em seus discursos do porquê viver em meio a perdas, solidão, isolamento, sensação de vazio, frustração existencial, dificuldades econômicas, sem saber o que realizar com seu tempo livre e como seguir a vida.

Essa esperança desponta quando se vislumbra a potência que o homem pode vir a ser. Independente de seu tempo transcorrido no caminho existencial, no exercício de sua liberdade e responsabilidade, o idoso tem a capacidade de dizer "sim à vida". Perseverando no caminho dos valores, a pessoa idosa pode e precisa continuar a orientar sua vida para algo ou alguém significativo, o "para quê viver" torna-se enriquecido. Manter um projeto de vida e a disposição para amar lhe permitem continuar a responder à vida de forma comprometida.

Quando nos deparamos com aqueles que se sentem valorizados pelo fato de poder cuidar dos seus netos, quando dispõem de tempo para serem voluntários, entregando-se generosamente a um serviço, por exemplo, quando podem aconselhar aos mais jovens, lançando mão da sabedoria conquistada, percebemos que a missão da vida continua, e que as oportunidades do momento possibilitam a busca de sentido, a qual não cessam com o tempo.

Mas importa que essa visão de esperança seja perceptível, não somente aos profissionais, mas, sobretudo, aos envolvidos diretamente nesse processo, aos idosos. Isso permitirá que acreditem em suas potencialidades, transcendendo, encontrando sentido nas situações adversas, para além dos estereótipos que cercam o envelhecer. Eis, aqui, o precioso trampolim no caminho da existência.

Torna-se possível ajudá-los a realizar o balanço da vida, considerando não somente as perdas nessa fase, mas acolhendo os ganhos que dela surgem. É preciso crer que, no tempo presente, há tarefas que o idoso pode realizar e, assim, permitir encontrar sentido na vida. Reconhecê-los como os "guardiões da memória coletiva", que deixam o legado da conquista vivida, o tesouro da sabedoria, que, compartilhado, ajudará aos que virão, passa a dar significados novos para o seu tempo, para sua vida.

Viver no caminho das escolhas responsáveis, na liberdade de continuar no campo das possibilidades, fomentando a esperança no potencial para viver, pode proporcionar ao idoso que essa etapa da vida seja vivida de modo pleno, com propósitos e com sentido.

Enfim, os caminhos das construções teóricas impulsionam e promovem o embasamento das nossas práticas, e estas podem ser mais acolhedoras e humanizadas, no que diz respeito ao cuidado do idoso. Espera-se que a tentativa de "ampliar o olhar" e fomentar a esperança, frente à população idosa, não se esgote neste artigo, mas que seja ponte para futuras reflexões. 


\section{Referências}

Amatuzzi, M.M. (2015). Psicologia do desenvolvimento religioso: a religiosidade nas fases da vida. São Paulo: Ideias e Letras.

Brasil. (2020). Ministério lança cartilha em benefício da população idosa. Brasília: Governo Federal. Recuperado a partir de https://www.gov.br/mdh/ pt-br/assuntos/noticias/2020-2/fevereiro/ministerio-lanca-cartilha-em-beneficio-da-populacao-idosa

Correa, A.C. de O. (2016). Psicologia do envelhecimento. Recuperado a partir de https:/antoniocarlosocorrea.wordpress.com/2016/12/11/27/

Debert, G.G. (2004). A reinvenção da velhice: socialização e processos de reprivatização do envelhecimento. São Paulo: Universidade de São Paulo (Fapesp).

Frankl, V.E. (2014). Em busca de sentido: um psicólogo no campo de concentração (36a ed.). Petrópolis: Vozes.

Frankl, V.E. (2016). Sede de sentido. (5a ed.). São Paulo: Quadrante.

Gatto, I. de B. (1999). Aspectos Psicológicos do Envelhecimento. In M. P. Netto (Org.), Gerontologia: a velhice e o envelhecimento em visão globalizada. (Cap. 11, pp. 109-113) São Paulo: Atheneu.

Instituto Brasileiro de Geografia e Estatística. (2017). PNAD 2016: População idosa cresce $16,0 \%$ frente a 2012 e chega a 29,6 milhões. Recuperado a partir de https://agenciadenoticias.ibge.gov. br/agencia-noticias/2013-agencia-denoticias/releases/18263-pnad-2016-populacao-idosa-cresce-16-0-frente-a-2012-e-chega-a-29-6-milhoes. html.

Instituto Brasileiro de Geografia e Estatística. (2018). Número de idosos cresce 18\% em 5 anos e ultrapassa 30 milhões em 2017, Brasília: IBGE, recuperado a partir de https://agenciadenoticias. ibge.gov.br/ agencia-noticias/2012-agencia-de-noticias/noticias/ 20980-numero-de-idosos-cresce-18-em-5-anos-e-ultrapassa-30-milhoes-em-2017.

Kroeff, P. (2014). Logoterapia e existência: a importância do Sentido da Vida. Porto Alegre: Evangraf.

Lukas, E. (1992). Prevenção psicológica: a prevenção de crises e a proteção do mundo interior do ponto de vista da Logoterapia. Petrópolis: Vozes.
Lukas, E. (2015). Psicologia Espiritual: fontes de uma vida plena de sentido. São Paulo: Paulus.

Melo, R.L.P. de, et al. (2013). Sentido de vida, dependência funcional e qualidade de vida em idosos. Revista Brasileira de Geriatria Gerontologia, 16 (2), pp. 239-250.

Ministério Da Saúde. (2006). Cadernos de Atenção Básica $\mathrm{n}^{0}$ 19: Envelhecimento e saúde da pessoa idosa, Brasília.

Neri, A.L. (2009). Saúde e envelhecimento: prevenção e promoção. As necessidades afetivas dos idosos. Conselho Federal de Psicologia, Brasília, 1, pp. 103-110.

Netto, M.P. (1996). Gerontologia: a velhice e o envelhecimento em visão globalizada. São Paulo: Atheneu.

Organização Mundial de Saúde (2005) Envelhecimento ativo: uma política de saúde. Brasília: World Health Organization.

Papalia, D.E., Olds, S.W. \& Feldman, R.D. (2007). Desenvolvimento humano. (8a ed.). Porto Alegre: Artmed.

Paschoal, S.M.P. (1996) Epidemiologia do Envelhecimento. In: M.P. Netto (Org); Gerontologia: A velhice e o envelhecimento em visão globalizada. (Cap. 03, pp. 26-43) São Paulo: Atheneu.

Pintos, C.C.G. (1992) O entardecer da existência: ajuda para o idoso viver feliz. Aparecida do Norte: Santuário.

Pinto, J.M. \& Neri, A.L. (2017). Trajetórias da participação social na velhice: uma revisão sistemática da literatura. Revista Brasileira de Geriatria e Gerontologia, 20(2), pp. 259-272. https://doi. org/10.1590/1981-22562017020.160077.

Rodrigues, R. (1991). Fundamentos da Logoterapia: na clínica psiquiátrica e psicoterapêutica. (Vol. 1), Petrópolis: Vozes.

Schneider, R.H. \& Irigaray, T.Q. (2008) O envelhecimento na atualidade: aspectos cronológicos, biológicos, psicológicos e sociais. Estudos de Psicologia. Campinas, 25(4), pp. 585-593.

Vaticano. (1999). Carta do Papa João Paulo II aos Anciãos. Recuperado a partir de https://w2.vatican. va/content/john-paul-ii/pt/letters/1999/documents/hf_jpii_let_01101999_elderly.html 
Cleia Zanatta (Orcid 0000-0002-9951-9771). Doutorado em Psicologia Social pela Universidade do Estado do Rio de Janeiro; Pós-Doutorado no Centro de Investigação em Psicologia (CIPsi), na Escola de Psicologia da

Universidade do Minho - Portugal (UMINHO); Mestrado em Psicologia pela Pontifícia Universidade Católica do Rio de Janeiro; Especialização em Psicologia Escolar/Educacional e Psicopedagogia; Graduação pela Universidade Católica de Petrópolis em Pedagogia, em Psicologia e em Direito; integrante do GT Psicologia e Religião vinculado à Associação Nacional de Pesquisa e Pós Graduação em Psicologia (ANPPEP); investigadora do Programa Internacional de Pesquisa Cátedras Scholas, vinculado ao Vaticano e do Grupo Universitário de Investigação em Autorregulação de Aprendizagem (GUIA) da Escola de Psicologia da Universidade do Minho- Portugal. Pesquisadora e Professora do Curso de Mestrado e Graduação em Psicologia da Universidade Católica de Petrópolis. e-mail: cleia.zanatta@ucp.br
Luís Antônio Monteiro Campos (Orcid https:// orcid.org/0000-0002-2707-5593). Psicólogo pela Universidade Federal do Rio de Janeiro, Mestre e Doutor em Psicologia pela Universidade Federal do Rio de Janeiro. Especialista em Logoterapia pela Sociedade Brasileira de Logoterapia. Membro da Sociedade Brasileira de Psicologia, Membro da Sociedade Americana de Psicologia. Atualmente é professor Universitário e Coordenador do Mestrado em Psicologia da UCP e professor da PUC-RIO. Participante do International Child Mental Health Study Group (ICMH-SG). e-mail: luis.campos@ucp. brPatricia Damiana da Silva Coelho (Orcid https:// orcid.org/0000-0002-5449-796X). Graduada em Psicologia pela Faculdade Maria Thereza, Especialista em Atendimento Psicanalítico e em Logoterapia e Análise Existencial. Psicóloga em Instituição de Longa Permanência para Idosos (1996-2008); Professora de Psicologia da FAETEC/RJ. Membro da Associação Brasileira de Logoterapia e Análise Existencial (ABLAE).
Recebido em 31.08.18

Primeira decisão editorial em 07.03.20

Segunda decisão editorial.13. 05.20

Terceira decisão editorial 02.07.20

Aceito em 15.07.20 